Research Article

\title{
Effects of $\beta$-Cyclodextrin and Sodium Ascorbate on the Chemical Compositions and Sensory Quality of Instant Green Tea Powder during Storage
}

\author{
Yan-Hong Zhang, ${ }^{1,2}$ Gen-Sheng Chen, ${ }^{2}$ Jian-Xin Chen, ${ }^{2}$ Zheng-Quan Liu $\left(\mathbb{D},{ }^{1}\right.$ \\ Liao-Yuan Yu, ${ }^{3}$ Jun-Feng Yin $\left(\mathbb{1},{ }^{2}\right.$ and Yong-Quan $\mathrm{Xu}\left(\mathbb{1}^{2}\right.$ \\ ${ }^{1}$ State Key Laboratory of Tea Plant Biology and Utilization, Anhui Agricultural University, Hefei, Anhui 230036, China \\ ${ }^{2}$ Tea Research Institute Chinese Academy of Agricultural Sciences, Key Laboratory of Tea Biology and Resources Utilization, \\ Ministry of Agriculture, Hangzhou 310008, China \\ ${ }^{3}$ Agricultural and Rural Department of Zhejiang Province, Hangzhou 310020, China
}

Correspondence should be addressed to Zheng-Quan Liu; liuzq0312@163.com and Yong-Quan Xu; yqx33@126.com

Received 20 December 2018; Revised 24 March 2019; Accepted 31 March 2019; Published 24 April 2019

Academic Editor: Bryan M. Wong

Copyright (c) 2019 Yan-Hong Zhang et al. This is an open access article distributed under the Creative Commons Attribution License, which permits unrestricted use, distribution, and reproduction in any medium, provided the original work is properly cited.

\begin{abstract}
The physicochemical changes of the instant green tea powders added with $\beta$-cyclodextrin and sodium ascorbate stored at $4^{\circ} \mathrm{C}$ and $25^{\circ} \mathrm{C}$ were investigated by determining moisture, polyphenols, caffeine, amino acids, catechins, color, sensory quality, and the total microbial count. The results showed that addition of both $\beta$-cyclodextrin $(6 \%, w / w)$ and sodium ascorbate $(2 \%$, w/w) reduced the changes of moisture, polyphenols, and catechins contents, helped to maintain the sensory quality, and limited the microbial count. The low temperature $\left(4^{\circ} \mathrm{C}\right)$ was also found to maintain the sensory quality and limit of the microbial count of instant green tea powder. The combination of low temperature and addition of $\beta$-cyclodextrin with sodium ascorbate were the best treatment for the storage of instant green tea powder. These results could provide useful information for the quality improvement of instant green tea powder during storage.
\end{abstract}

\section{Introduction}

Green tea is popular in Asian countries such as China and Japan. It is a nonfermented tea and contains more polyphenols than oolong tea and black tea. More than 1.5 million tons of green tea were produced and consumed in China in 2016 [1]. Green tea has been reported to have many physiological functions, such as reduction of risk of cardiovascular diseases, cancers, antibacterial and anti-inflammatory properties, and body weight control [2].

Instant tea powder is the major tea extract product with an annual production of more than 20,000 tons [3]. The instant tea powder is mostly used for preparing the mixed tea beverage, bakery products, snacks, and other foods containing tea flavors. The traditional drying method for instant tea is spray drying [4]. Freeze-drying is used to improve the quality of instant green tea powder due to avoiding the hightemperature-induced degradation of nutrients and damages of instant tea flavor [5]. Similar to instant coffee, now more and more instant tea powder is used for drinking after brewing with cold or hot water. However, the sensory quality (including taste and aroma) of instant tea powder can be significantly influenced during the storage [6].

Cyclodextrins act as molecular encapsulants, protecting the flavor in many rigorous food-processing methods like drying, thawing, and microwaving [7]. The $\beta$-cyclodextrin allows the flavor quality and quantity to be preserved to a greater extent and longer period compared to other encapsulants and provides longevity to the food items [8]. Ascorbic acid is also widely used as an antioxidant in tea beverage or tea product to protect the nutrients and flavor from losses during the processing and storage $[9,10]$. 
However, up to our knowledge, there are no studies that have been conducted to evaluate the possibility of addition of $\beta$-cyclodextrin and ascorbic acid to extend the shelf-life of instant tea powder.

This study was conducted to evaluate the effectiveness of $\beta$-cyclodextrin and sodium ascorbate in maintaining the quality of instant green tea powder in terms of sensory quality, chemical components, and the total microbial count.

\section{Materials and Methods}

2.1. Chemicals. Caffeine and catechins were purchased from Sigma, Shanghai, China. $\beta$-Cyclodextrin and sodium ascorbate were purchased from Xi'an Yuhua Biotechnology Co., Ltd. Pure water used in this study was obtained from Hangzhou Wahaha Group Co., Ltd. (Hangzhou, China). The $\mathrm{pH}$ was $6.75 \pm 0.03$, and its electroconductivity was $1.82 \pm 0.07 \mu \mathrm{S} / \mathrm{cm}$.

2.2. Instant Green Tea Preparation and Storage. Green tea was purchased from a tea market in Wuyi county, which is in the middle part of Zhejiang Province. The green tea was smashed and passed the sieve to obtain mesh sizes ranging from 20 to 40 . The smashed tea leaves were soaked in a stainless steel tank of $55^{\circ} \mathrm{C}$ for $30 \mathrm{~min}$. The tea was clarified by filtration with the UF membrane (100,000 dalton) and concentrated with the RO membrane (Hydrotech Separation Technology Co. Ltd., Beijing, China). The concentrated tea steep was 15.6 Brix and freeze-dried by freeze dryers (FTS13TD, KINETICS LTD, America). Before freeze-drying, 6\% $\beta$-cyclodextrin and $2 \%$ sodium ascorbate (according to the instant tea powder, w/w) were added into concentrated tea. And three samples of instant green tea powder $(6 \% \beta$-cyclodextrin, $6 \% \beta$-cyclodextrin and $2 \%$ sodium ascorbate, and control) were obtained. The dried instant green tea was yellow powder and was packed with three-layer multiple material (PET $30 \mu \mathrm{m}$-aluminium foil $30 \mu \mathrm{m}$-PE $50 \mu \mathrm{m}$ ) for $0.75 \pm 0.05 \mathrm{~g}$ per bag. The packed instant green tea bags were randomly and averagely divided into two groups. One group was stored at $4^{\circ} \mathrm{C}$ in a refrigerator, and the another group was stored at room temperature of $25^{\circ} \mathrm{C}$ as the normal temperature of Hangzhou.

2.3. Infusion of the Instant Green Tea Preparation. The green tea infusion was prepared by dissolving $0.75 \mathrm{~g}$ of the instant green tea powder in $150 \mathrm{~mL}$ water at room temperature of $25^{\circ} \mathrm{C}$. The tea infusion was used for determining chemicals and scoring sensory quality.

2.4. Analysis of Moisture Content. Moisture contents of the instant green tea powders were determined according to QB/ $\mathrm{T}$ 4067-2010, which was constituted referring to ISO 7513 (2007). The instant green tea powders were dried at $103 \pm 2^{\circ} \mathrm{C}$ for $2 \mathrm{~h}$, and moisture contents were expressed in percentage.
2.5. Analysis of Amino Acids. The contents of amino acids in tea infusions were determined by a spectrophotometer with ninhydrin dyeing's method [1], which determined at $540 \mathrm{~nm}$ with glutamic acid as the standard amino acid. The standard amino acid formula is as follows:

$$
\begin{aligned}
{[C] } & =\frac{([A]+0.0868)}{1.51}, \\
R^{2} & =0.9996 .
\end{aligned}
$$

2.6. Analysis of Tea Polyphenols. The contents of tea polyphenols in the above tea infusions were determined by the spectrophotometric method with $\mathrm{FeSO}_{4}, 3.5 \times 10^{-3} \mathrm{M}$ potassium sodium tartrate and buffer described by Zhong [11]. The absorbance (E1) at $540 \mathrm{~nm}$ of the reaction solution was determined in a $1 \mathrm{~cm}$ lightpath cell by a spectrophotometer (Shanghai, China). The absorbance (E2) at $540 \mathrm{~nm}$ of a control reaction solution (containing $5 \mathrm{~mL}$ distilled water, $5 \mathrm{~mL}$ dyeing solution, and $15 \mathrm{~mL}$ buffer) was determined as earlier. The content of tea polyphenols was calculated by the following equation:

$$
\mathrm{TP}\left(\mathrm{g} \cdot 100 \mathrm{~mL}^{-1}\right)=\left(E_{1}-E_{2}\right) \times \frac{3.9133}{10} .
$$

2.7. Analysis of Color Difference of Tea Infusions. The color difference analysis of tea infusion was carried out using a model of MINOLTA CT-310 automatic color difference meter (Konica Minolta (China) Investment, Ltd, Shanghai, China). Distilled water was used as control, and the color difference indicators $L, a$, and $b$ that represent the light-dark $(L)$, red-green $(a)$, and yellow-blue $(b)$ in the threedimensional color coordinate system between the tea infusion and the distilled water were read [12].

2.8. Analysis of Catechins and Caffeine. Analysis of catechins and caffeine was carried out by the HPLC method according to the method that was described by Tang et al. [13]. The tea infusions were filtered through a $0.2 \mu \mathrm{m}$ Millipore filter before injection (Model Shimadzu LC2010A, Shimadzu Corporation, Kyoto, Japan). The HPLC conditions were as follows: injection volume, $5 \mu \mathrm{L}$; column, $5 \mu \mathrm{m}$-Diamonsil ${ }^{\mathrm{TM}} \mathrm{C} 18(4.6 \mathrm{~mm} \times 250 \mathrm{~mm})$; temperature, $40^{\circ} \mathrm{C}$; mobile phase $\mathrm{A}$, acetonitrile/acetic acid/ water $(6: 1: 193)$; mobile phase $\mathrm{B}$, acetonitrile/acetic acid/ water ( $60: 1: 193)$; gradient, $100 \%$ mobile phase A to $100 \%$ mobile phase B by linear gradient during the early $45 \mathrm{~min}$ and then $100 \%$ mobile phase $B$ up to $60 \mathrm{~min}$; flow rate, $1 \mathrm{~mL} \mathrm{~min}^{-1}$; and detector, Shimadzu SPD ultraviolet detector (Shimadzu Corporation, Kyoto, Japan) at $280 \mathrm{~nm}$.

2.9. Sensory Quality Assessment of Instant Green Tea. A $0.5 \mathrm{~g}$ of instant green tea was infused with $100 \mathrm{~mL}$ distilled water $\left(25^{\circ} \mathrm{C}\right)$ for $30 \mathrm{~s}$. The quality of the instant green tea was estimated and scored by 7 professional tea tasters from Tea Research Institute of Chinese Academy of Agricultural Sciences. Scores for different sensory qualities, including aroma, 


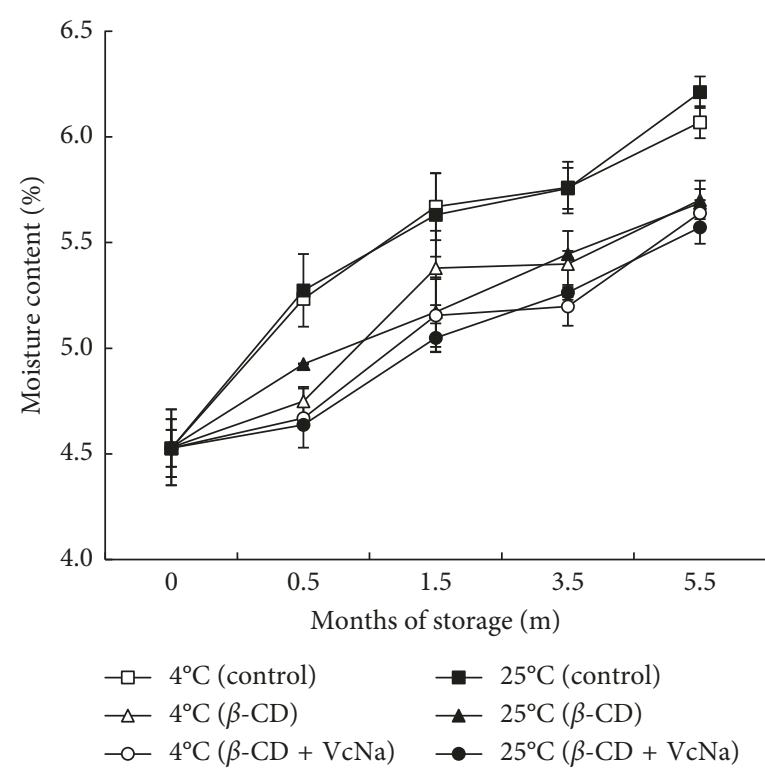

(a)

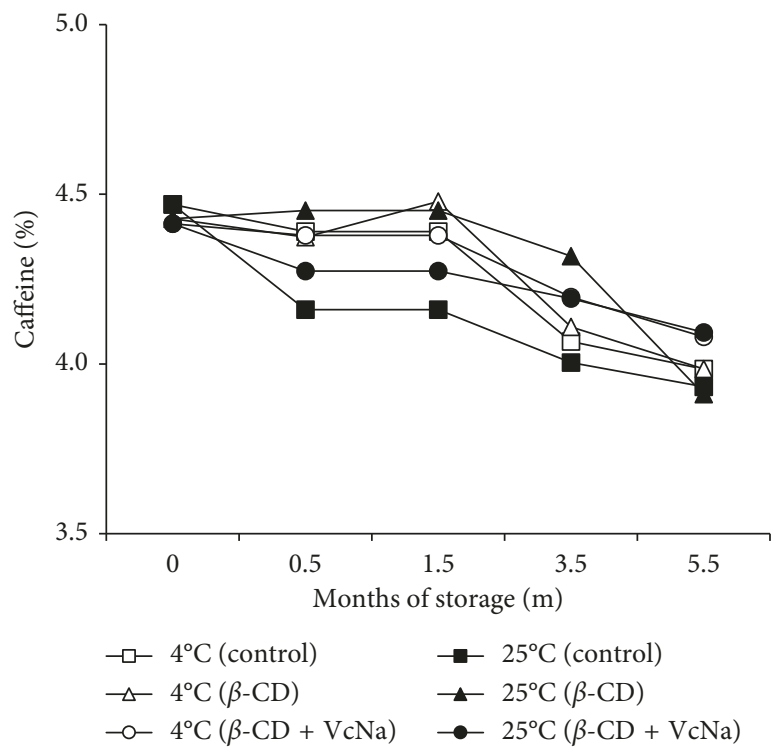

(c)

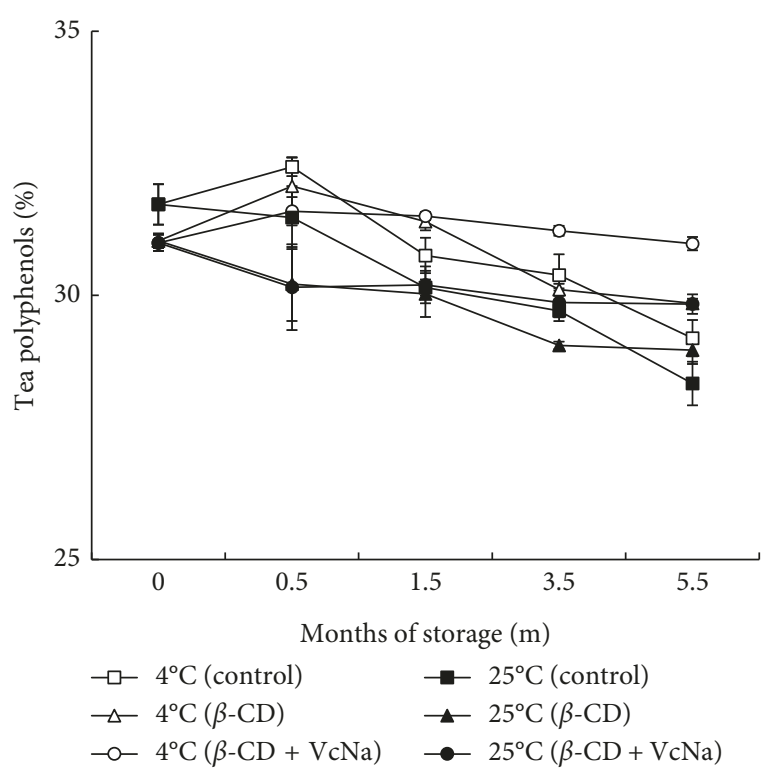

(b)

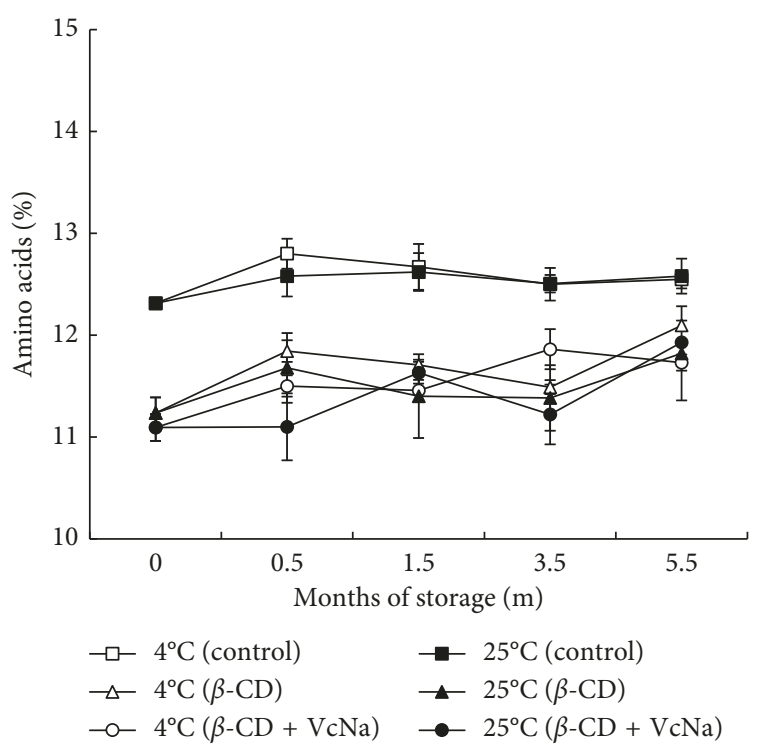

(d)

FIGURE 1: Contents of moisture and main chemical components in instant green tea samples during storage: (a) moisture content; (b) tea polyphenols; (c) caffeine; (d) amino acids. $\beta$-CD: $\beta$-cyclodextrin; VcNa: sodium ascorbate.

taste, and overall acceptability, were given by each member of the team. The traditional nine-point scale was modified to a ten-point scale where 8-10 was "extremely strong," 6-8 "strong," 4-6 "neutral," 2-4 "weak," and 0-2 "extremely weak" [14]. The results were analysed statistically to determine any differences between the mean scores for the different samples. Each evaluation was replicated three times on different days with a random order of samples for each test.

2.10. Microbiological Analysis. The determination of aerobic bacterial count was according to Chinese QB/T 4067-2010, and the counts were defined as cfu/g. Analysis of microorganism was accomplished by Tea Quality Supervision and Inspection Centre (Ministry of Agriculture, P. R. China).
2.11. Statistical Analysis. The results were expressed as a mean of three replicates with standard deviation. Analysis of variance and significant differences among means was performed with one-way ANOVA using SPSS 16.5 (IBM, Armonk, NY).

\section{Results and Discussion}

3.1. Moisture and Main Chemicals. The contents of moisture and main chemicals in the instant green tea powders changed obviously during storage (Figure 1). The contents of moisture in the instant tea powders were increased in all samples. The addition of $\beta$-cyclodextrin and sodium ascorbate inhibited the increase of moisture contents during 
the storage at $4^{\circ} \mathrm{C}$ and $25^{\circ} \mathrm{C}$. Compared to the control, the addition of $\beta$-cyclodextrin inhibited the increase of moisture contents for $0.40 \%$ and $0.56 \%$ at $4{ }^{\circ} \mathrm{C}$ and $25^{\circ} \mathrm{C}$ after 5.5 months storage (Figure 1(a)). However, the moisture contents between the addition of $\beta$-cyclodextrin and the addition of $\beta$-cyclodextrin with sodium ascorbate were not significantly different (Figure 1(a)). The instant (soluble) green tea powders were found to adsorb easily moisture during storage at different temperatures $\left(20-50^{\circ} \mathrm{C}\right)$ [6]. The moisture sorption of instant green tea powder increased with the storage relative humidity (43-97\%) [15]. From the above results, it can be indicated that the addition of $\beta$-cyclodextrin helps to inhibit the increase of moisture contents of instant green tea powder during storage.

As shown in Figures 1(b)-1(d), the contents of polyphenols and caffeine in the instant green tea powders were decreased greatly during the storage, and the contents of amino acids changed slightly during the storage both at $4^{\circ} \mathrm{C}$ and $25^{\circ} \mathrm{C}$. Either lower temperature $\left(4^{\circ} \mathrm{C}\right)$ or sodium ascorbate helped hold the contents of polyphenols during the storage. However, only the content of polyphenols in the instant tea powders with addition of $\beta$-cyclodextrin and sodium ascorbate stored at $4^{\circ} \mathrm{C}$ was obviously higher than those of the other treatments after 3.5 months of storage. Addition of $\beta$-cyclodextrin and sodium ascorbate helped hold the contents of caffeine in the instant tea powders during the storage. However, there was no significant difference between different treatments (control and addition of $\beta$-cyclodextrin at 4 and $25^{\circ} \mathrm{C}$ ). The contents of amino acids in the instant tea powder samples without addition were higher than the other samples. The $\beta$-cyclodextrin significantly reduced the contents of amino acids. And the contents of amino acids in instant tea powder slightly increased during the storage, but there was no significant difference (Figure 1(d)). The main reason was that the hydrolysis of water soluble protein led to the increase of amino acids; on the other hand, amino acids were oxidized, degraded, and transformed, which led to the decrease of amino acids. Polyphenols, especially EGCG, was found to be easily degraded in both solution and solid states during the storage [16]. Except polyphenols, the storage temperatures (4 and $25^{\circ} \mathrm{C}$ ) were not found significantly to influence the contents of caffeine and amino acids during the storage.

3.2. Catechins. Catechins, the main contributors to the taste and health benefits of green tea mainly include EGCG, (-)-epigallocatechin, (-)-epicatechin gallate, and $(-)$-epicatechin. The contents of catechins in the instant green tea powders were significantly decreased during the storage (Figure 2). After 5.5 months of storage, the contents of catechins in the instant green tea powders stored at $4^{\circ} \mathrm{C}$ were higher than those stored at $25^{\circ} \mathrm{C}$, and the contents of catechins in the instant tea powders added with sodium ascorbate were higher than those without additions. Compared to the controls stored at 4 and $25^{\circ} \mathrm{C}$, the contents of catechins in the instant tea powders added with $\beta$-cyclodextrin were not significantly different (Figure 2 ). Catechins degradation was easily found not only in

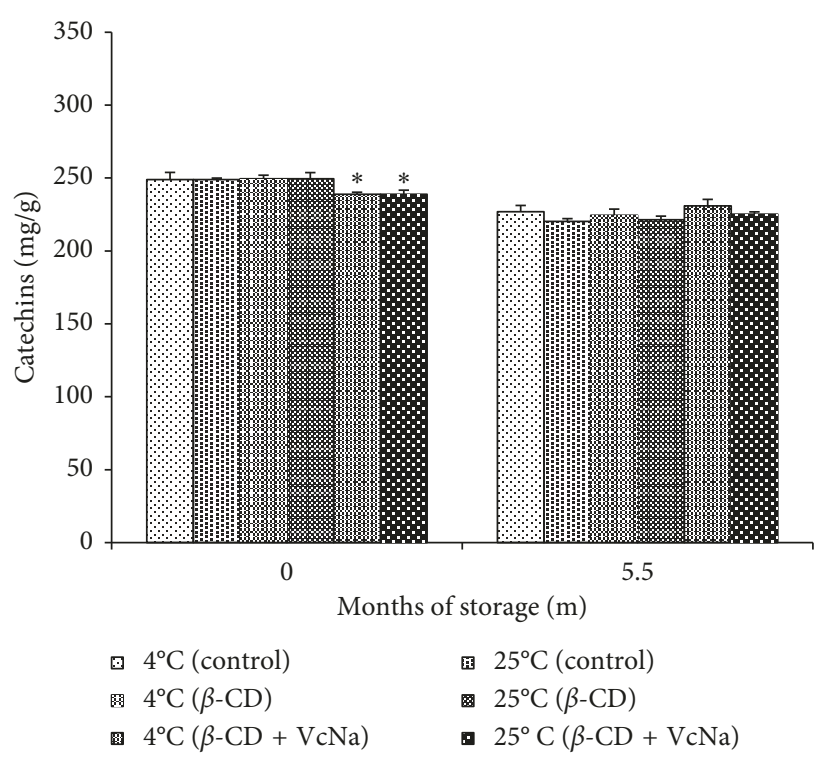

FIGURE 2: Contents of catechins in instant green tea samples during storage. $\beta$-CD: $\beta$-cyclodextrin; $\mathrm{VcNa}$ : sodium ascorbate.

solution [17, 18] but also in green tea powder [19] and commercial tea leaves [20] during storage. The degradation of catechins in instant green tea powders was affected by the storage temperature and relative humidity, and the storage temperature was the dominant factor [21]. Sodium ascorbate was found to significantly increase the stability of green tea catechins that incubated in the sodium phosphate buffer $(\mathrm{pH}=7.42)$ [22]. The above results showed that the low temperature of $4^{\circ} \mathrm{C}$ and sodium ascorbate helped inhibit the degradation of catechins.

3.3. Color. The colors of tea infusions contribute not only to their appearance but also to their agreeableness, which linked to both taste and flavor. The color of the tea infusions prepared with the instant green tea powder was also influenced by the storage conditions. With the extending of the storage time, the values of $L^{*}$ were decreased, and the values of $a^{*}$ and $b^{*}$ were increased (Figure 3 ). The values of $a^{*}$ and $b^{*}$ of the tea infusions prepared from the instant green tea powders stored at $25^{\circ} \mathrm{C}$ were higher than those stored at $4^{\circ} \mathrm{C}$. However, there was no significant difference between the instant green tea samples stored at the same temperature. In another study, the values of $L^{*}$ were also found to decrease, and the values of $a^{*}$ and $b^{*}$ were found to increase during the storage of tea beverages (including green tea, oolong tea, black tea, and pu'er tea), which was considered due to the oxidation of polyphenols [9]. The above results showed that the low temperature storage helped inhibit the change of the color of the instant green tea powder during the storage.

3.4. Sensory Quality. The sensory quality of the tea infusions prepared with the instant green tea was significantly influenced during the storage. With the extending of the storage, the scores of aroma, taste, and overall acceptability were gradually decreased (Figure 4). The scores for aroma, taste, 


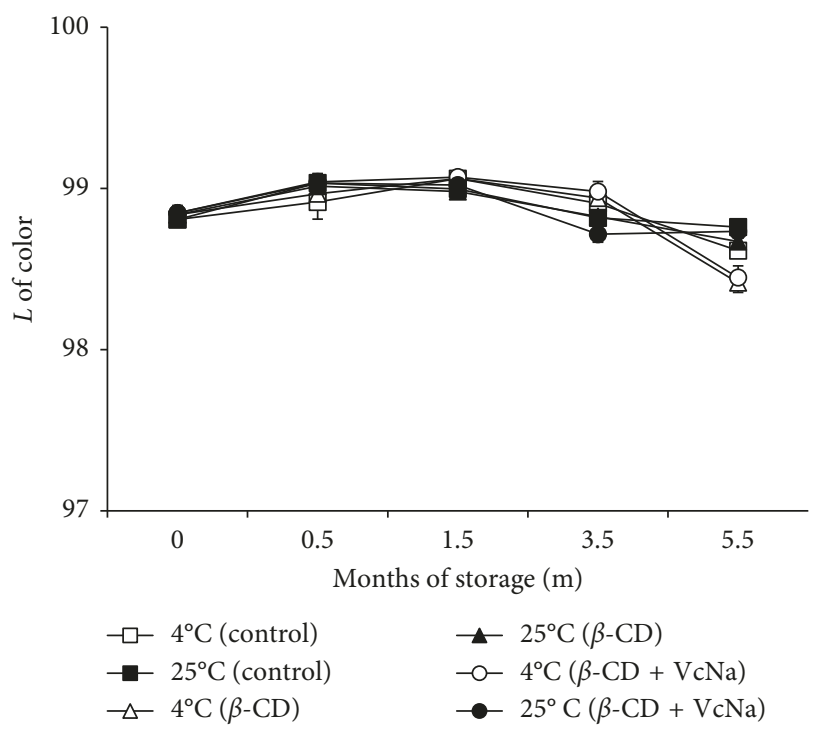

(a)

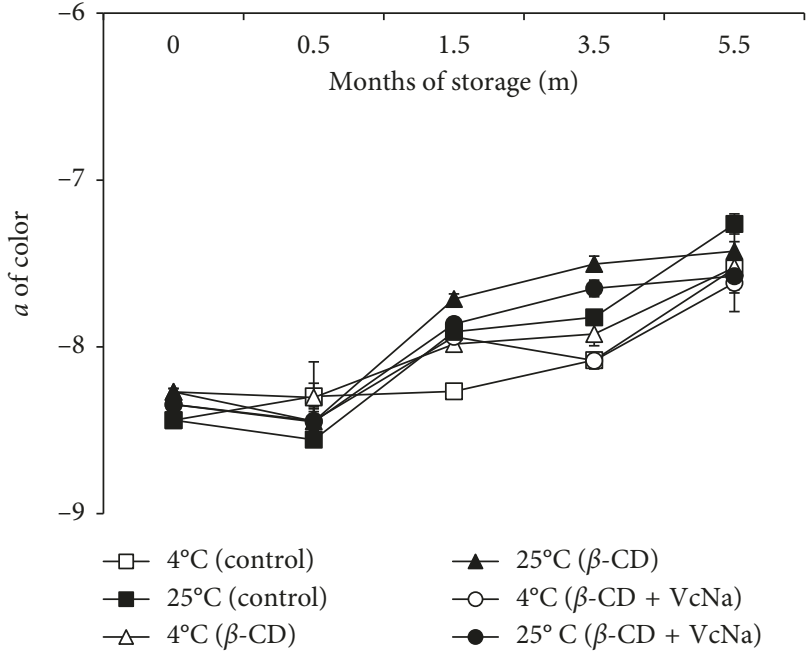

(b)

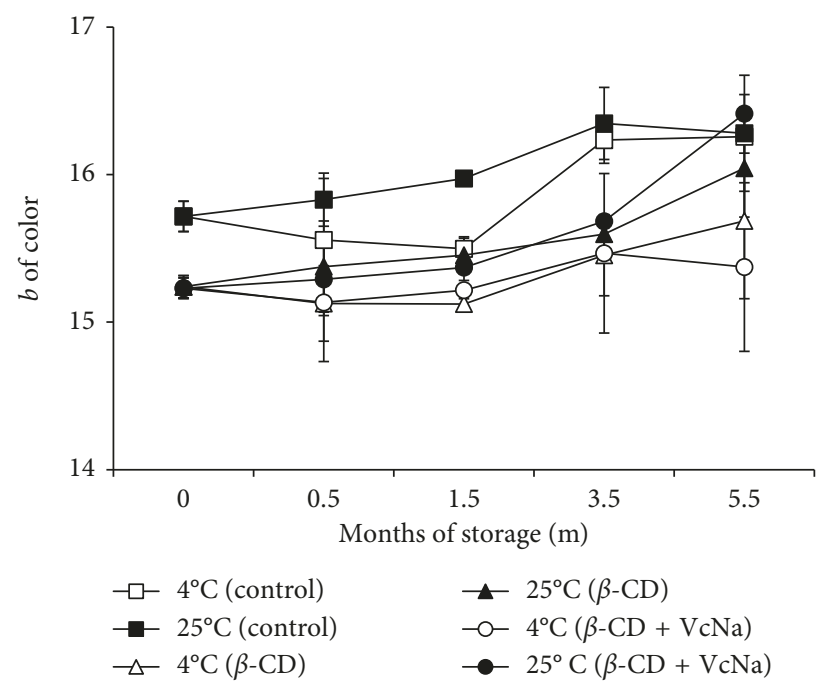

(c)

FIGURE 3: Color of green tea infusions prepared from instant green tea samples during storage: (a) $L$ of color; (b) $a$ of color; (c) $b$ of color. $\beta$-CD: $\beta$-cyclodextrin; $\mathrm{VcNa}$ : sodium ascorbate.

and overall acceptability of the tea infusions prepared from the instant green tea powders stored at $25^{\circ} \mathrm{C}$ were significantly lower than those at $4^{\circ} \mathrm{C}$. The scores of aroma, taste, and overall acceptability for the instant tea powder added $\beta$-cyclodextrin and sodium ascorbate stored at $4^{\circ} \mathrm{C}$ were much higher than those of the others (Figure 4). But addition of $\beta$-cyclodextrin was not found to hold the sensory quality during the storage. And there was no significant difference in the scores for aroma, taste, and overall acceptability between the instant tea samples stored at $25^{\circ} \mathrm{C}$. Former study showed that the addition of sodium ascorbate helped increase the stability of catechins and hold the sensory quality of green tea beverage and oolong tea beverage $[9,22]$ Sodium ascorbate, as an antioxidant (similar to ascorbic acid), helps reduce the oxidation and degradation of polyphenols, which are the main quality compositions in green tea $[9,23]$. The above results showed that low temperature of $4^{\circ} \mathrm{C}$ and addition of $\beta$-cyclodextrin with sodium ascorbate help hold the sensory quality of instant green tea.

3.5. Total Microbial Count. There were significant influences of ascorbic acid, $\beta$-cyclodextrin, and low-temperature storage on the total microbial counts in instant green tea powders during storage (Table 1). The total microbial counts in the instant tea were significantly increased during the storage. There was no visible microbe in the instant green tea powders containing $\beta$-cyclodextrin and sodium ascorbate stored at $4^{\circ} \mathrm{C}$ for 5.5 months and $25^{\circ} \mathrm{C}$ for 3.5 months. The total microbial counts of the instant tea powder added with $\beta$-cyclodextrin and sodium ascorbate was lower than that of the instant tea powder added with $\beta$-cyclodextrin alone at $25^{\circ} \mathrm{C}$. The total microbial counts in the instant tea stored at $4^{\circ} \mathrm{C}$ were significantly lower than those stored at $25^{\circ} \mathrm{C}$ (Table 1). Addition 


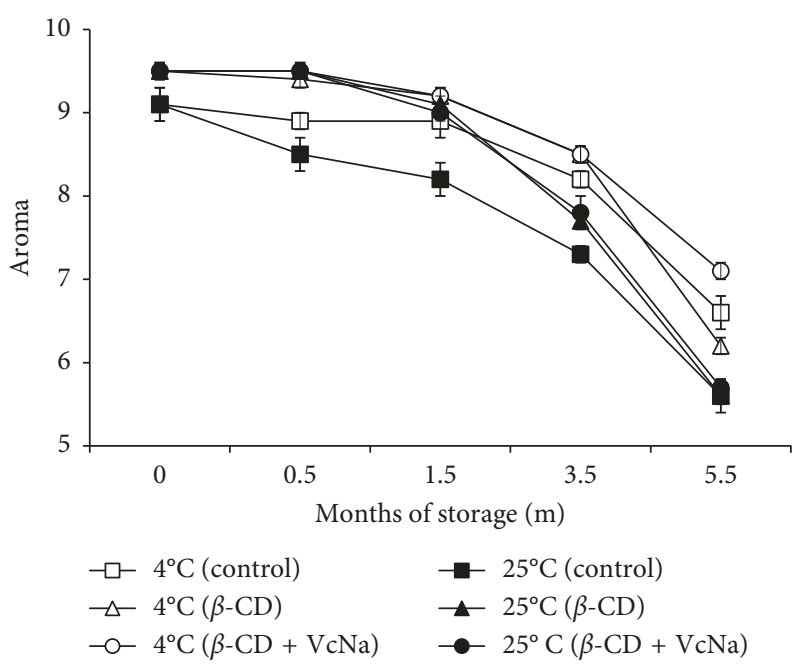

(a)

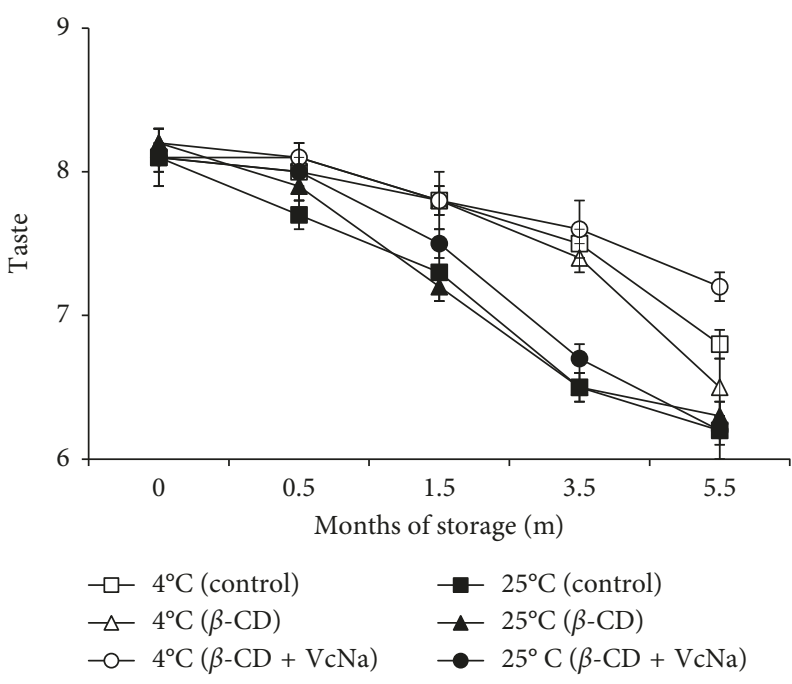

(b)

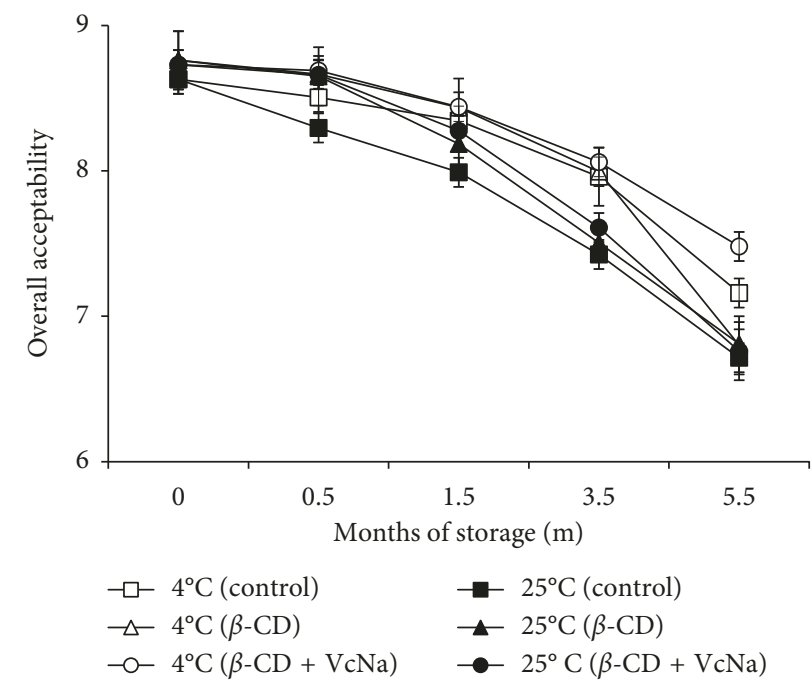

(c)

FIGURE 4: Sensory quality of green tea infusions prepared from instant green tea samples during storage: (a) aroma; (b) taste; (c) overall acceptability. $\beta$-CD: $\beta$-cyclodextrin; $\mathrm{VcNa}$ : sodium ascorbate.

TABLE 1: Total microbial count in instant green tea powder during storage $(\mathrm{cfu} / \mathrm{g})$.

\begin{tabular}{lcccc}
\hline Months & 0 & 1.5 & 3.5 & 5.5 \\
\hline $4^{\circ} \mathrm{C}$ & & & & \\
Control & $<10^{\mathrm{a}}$ & $20 \pm 10^{\mathrm{b}}$ & $120 \pm 20^{\mathrm{c}}$ & $250 \pm 30^{\mathrm{c}}$ \\
$\beta-\mathrm{CD}$ & $<10^{\mathrm{a}}$ & $<10^{\mathrm{c}}$ & $<10^{\mathrm{d}}$ & $200 \pm 20^{\mathrm{c}}$ \\
$\beta-\mathrm{CD}+\mathrm{VcNa}$ & $<10^{\mathrm{a}}$ & $<10^{\mathrm{c}}$ & $<10^{\mathrm{d}}$ & $<10^{\mathrm{e}}$ \\
\hline $25^{\circ} \mathrm{C}$ & & & & \\
Control & $<10^{\mathrm{a}}$ & $50 \pm 10^{\mathrm{a}}$ & $300 \pm 20^{\mathrm{a}}$ & $800 \pm 20^{\mathrm{b}}$ \\
$\beta-\mathrm{CD}$ & $<10^{\mathrm{a}}$ & $30 \pm 10^{\mathrm{b}}$ & $200 \pm 10^{\mathrm{b}}$ & $1000 \pm 50^{\mathrm{a}}$ \\
$\beta-\mathrm{CD}+\mathrm{VcNa}$ & $<10^{\mathrm{a}}$ & $<10^{\mathrm{c}}$ & $<10^{\mathrm{d}}$ & $100 \pm 10^{\mathrm{d}}$ \\
\hline
\end{tabular}

$\beta$-CD: $\beta$-cyclodextrin; VcNa: sodium ascorbate. ${ }^{\mathrm{a}, \mathrm{b}, \mathrm{c}, \mathrm{d}, \mathrm{e}}$ Significant differences at the level $p<0.05$.

of $\beta$-cyclodextrin and sodium ascorbate in the instant tea powders stored at low temperature might retard the growth of organisms. In a former study, sodium ascorbate was also found to significantly reduce the total microbial counts in sugarcane juice during storage [10]. Another study demonstrated that sodium ascorbate could act as a signal modulator and virulence inhibitor in $P$. aeruginosa [24]. So, the addition of sodium ascorbate in the instant tea powders can help retard the growth of organisms and hold the sensory quality.

\section{Conclusion}

The present study investigated the effects of $\beta$-cyclodextrin and sodium ascorbate on the quality of the instant tea powders during storage. During the storage, the moisture contents of the instant tea powders were increased, the contents of total polyphenols and caffeine were decreased, and the scores of aroma, taste, and overall acceptability decreased obviously. There was no significant difference in the contents of the chemical compositions (except catechins) between different treatments during storage. However, low temperature $\left(4^{\circ} \mathrm{C}\right)$ and the addition of $\beta$-cyclodextrin and 
sodium ascorbate were found to maintain the sensory quality of the instant green tea powders better than the control samples and the instant tea powders containing $\beta$-cyclodextrin during the storage. Additions of $\beta$-cyclodextrin and sodium ascorbate and low temperature were also found to retard the growth of organisms. These results can provide useful information for the quality improvement of instant green tea powder during storage.

\section{Data Availability}

The data used to support the findings of this study are included within the article.

\section{Conflicts of Interest}

The authors declare that there are no conflicts of interest regarding the publication of this paper.

\section{Authors' Contributions}

Yan-Hong Zhang and Gen-Sheng Chen contributed equally to this work.

\section{Acknowledgments}

This research was supported by the National Key Research and Development Program of China (2017YFD0400800), the Agricultural Major Technologies Cooperative Extension of Zhejiang (2018XTTGCY02), and the Key Research and Development Program of Zhejiang (2019C02072).

\section{References}

[1] Y.-Q. Xu, W.-B. Ji, P. Yu, J.-X. Chen, F. Wang, and J.-F. Yin, "Effect of extraction methods on the chemical components and taste quality of green tea extract," Food Chemistry, vol. 248, pp. 146-154, 2018.

[2] C. Cabrera, R. Artacho, and R. Giménez, "Beneficial effects of green tea-a review," Journal of the American College of Nutrition, vol. 25, no. 2, pp. 79-99, 2006.

[3] J. Yin, S. Fu, X. Liu, and C. Lu, "Safety issues in tea deepprocessing products in China and their counter-measures (in Chinese)," Journal of Food Sciences and Technology, vol. 32, no. 2, pp. 20-23, 2014.

[4] V. Kraujalyte, E. Pelvan, and C. Alasalvar, "Volatile compounds and sensory characteristics of various instant teas produced from black tea," Food Chemistry, vol. 194, pp. 864-872, 2016.

[5] W. Wang, S. Wu, X. Wu, B. Lu, and Y. Chen, "Influence of different drying methods on sensory evaluation of instant black tea (in Chinese)," Journal of Zhangzhou Institute of Technology, vol. 19, no. 3, pp. 56-59, 2017.

[6] V. R. Sinija and H. N. Mishra, "Moisture sorption isotherms and heat of sorption of instant (soluble) green tea powder and green tea granules," Journal of Food Engineering, vol. 86, no. 4, pp. 494-500, 2008.

[7] E. M. M. Del Valle, "Cyclodextrins and their uses: a review," Process Biochemistry, vol. 39, no. 9, pp. 1033-1046, 2004.

[8] S. Muñoz-Botella, B. Del Castillo, and M. A. Martyn, "Cyclodetrin properties andapplications of inclusion complex formation," ARS Pharmaceutica, vol. 36, no. 2, pp. 187-198, 1995.
[9] P. Liu, Y. Xu, C. Zou et al., "Studies on the quality change of tea infusion beverages during sterilization and storage (in Chinese)," Journal of Chinese Institute of Food Science and Technology, vol. 18, no. 1, pp. 202-210, 2018.

[10] L. C. Mao, Y. Q. Xu, and F. Que, "Maintaining the quality of sugarcane juice with blanching and ascorbic acid," Food Chemistry, vol. 104, no. 2, pp. 740-745, 2007.

[11] L. Zhong, Methods of Chemical and Physical Evaluation of Tea Quality, Shanghai Science and Technology Press, Shanghai, China, 1989.

[12] Y. Liang, J. Lu, L. Zhang, S. Wu, and Y. Wu, "Estimation of tea quality by infusion colour difference analysis," Journal of the Science of Food and Agriculture, vol. 85, no. 2, pp. 286-292, 2005.

[13] P. Tang, D.-Y. Shen, Y.-Q. Xu, X.-C. Zhang, J. Shi, and J.-F. Yin, "Effect of fermentation conditions and plucking standards of tea leaves on the chemical components and sensory quality of fermented juice," Journal of Chemistry, vol. 2018, Article ID 4312875, 7 pages, 2018.

[14] Y.-Q. Xu, C. Zou, Y. Gao et al., "Effect of the type of brewing water on the chemical composition, sensory quality and antioxidant capacity of Chinese teas," Food Chemistry, vol. 236, pp. 142-151, 2017.

[15] N. Li, L. S. Taylor, and L. J. Mauer, "Degradation kinetics of catechins in green tea powder: effects of temperature and relative humidity," Journal of Agricultural and Food Chemistry, vol. 59, no. 11, pp. 6082-6090, 2011.

[16] N. Li, L. S. Taylor, M. G. Ferruzzi, and L. J. Mauer, "Color and chemical stability of tea polyphenol (-)-epigallocatechin-3gallate in solution and solid states," Food Research International, vol. 53, no. 2, pp. 909-921, 2013.

[17] Z.-Y. Chen, Q. Y. Zhu, D. Tsang, and Y. Huang, "Degradation of green tea catechins in tea drinks," Journal of Agricultural and Food Chemistry, vol. 49, no. 1, pp. 477-482, 2001.

[18] N. Li, L. S. Taylor, M. G. Ferruzzi, and L. J. Mauer, "Kinetic study of catechin stability: effects of $\mathrm{pH}$, concentration, and temperature," Journal of Agricultural and Food Chemistry, vol. 60, no. 51, pp. 12531-12539, 2012.

[19] J. Ortiz, M. G. Ferruzzi, L. S. Taylor, and L. J. Mauer, "Interaction of environmental moisture with powdered green tea formulations: effect on catechin chemical stability," Journal of Agricultural and Food Chemistry, vol. 56, no. 11, pp. 4068-4077, 2008.

[20] M. Friedman, C. E. Levin, S.-H. Choi, S.-U. Lee, and N. Kozukue, "Changes in the composition of raw tea leaves from the Korean Yabukida plant during high-temperature processing to pan-fried Kamairi-cha green tea," Journal of Food Science, vol. 74, no. 5, pp. C406-C412, 2009.

[21] J. Ortiz, U. S. Kestur, L. S. Taylor, and L. J. Mauer, "Interaction of environmental moisture with powdered green tea formulations: relationship between catechin stability and moistureinduced phase transformations," Journal of Agricultural and Food Chemistry, vol. 57, no. 11, pp. 4691-4697, 2009.

[22] Z.-Y. Chen, Q. Y. Zhu, Y. F. Wong, Z. Zhang, and H. Y. Chung, "Stabilizing effect of ascorbic acid on green tea catechins," Journal of Agricultural and Food Chemistry, vol. 46, no. 7, pp. 2512-2516, 1998.

[23] T. Tanaka, Y. Matsuo, and I. Kouno, "Chemistry of secondary polyphenols produced during processing of tea and selected foods," International Journal of Molecular Sciences, vol. 11, pp. 14-40, 2010.

[24] S. A. EI-Mowafy, M. I. Shaaban, and K. H. Abd EI Galil, "Sodium ascorbate as a quorum sensing inhibitor of Pseudomonas aeruginosa," Journal of Applied Microbiology, vol. 117, pp. 1388-1399, 2014. 

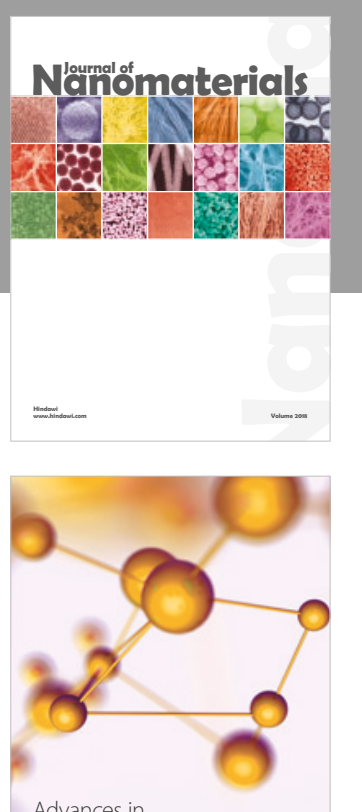

Physical Chemistry
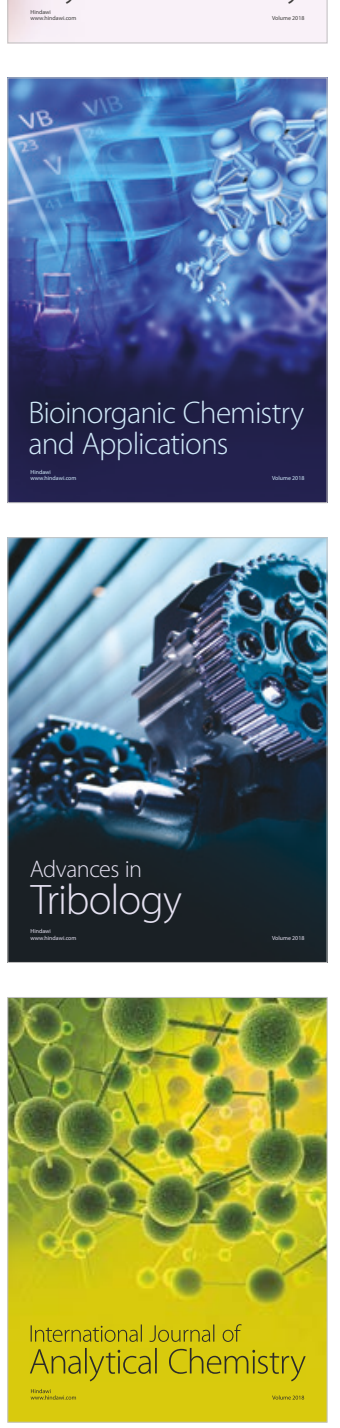

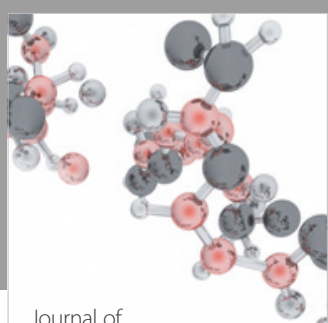

Analytical Methods

in Chemistry

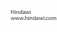

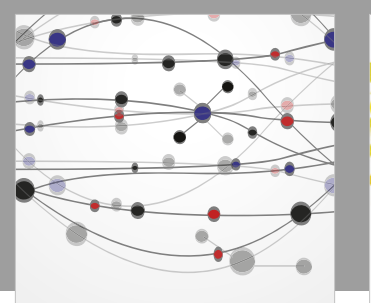

The Scientific World Journal

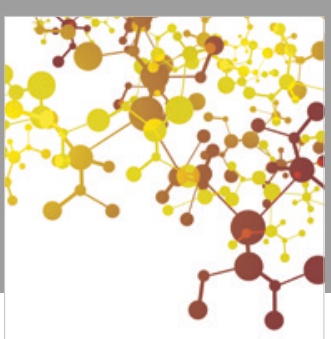

Journal of

Applied Chemistry
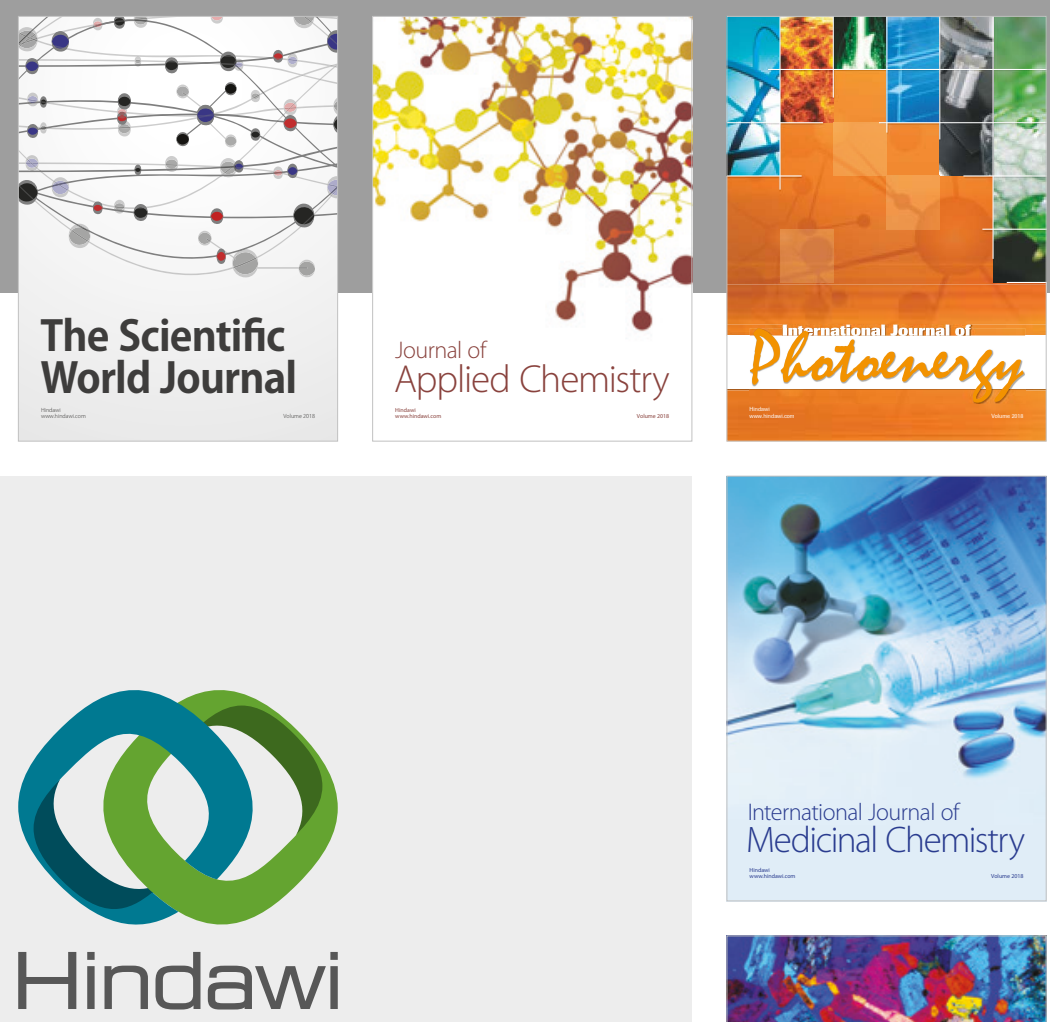

Submit your manuscripts at

www.hindawi.com
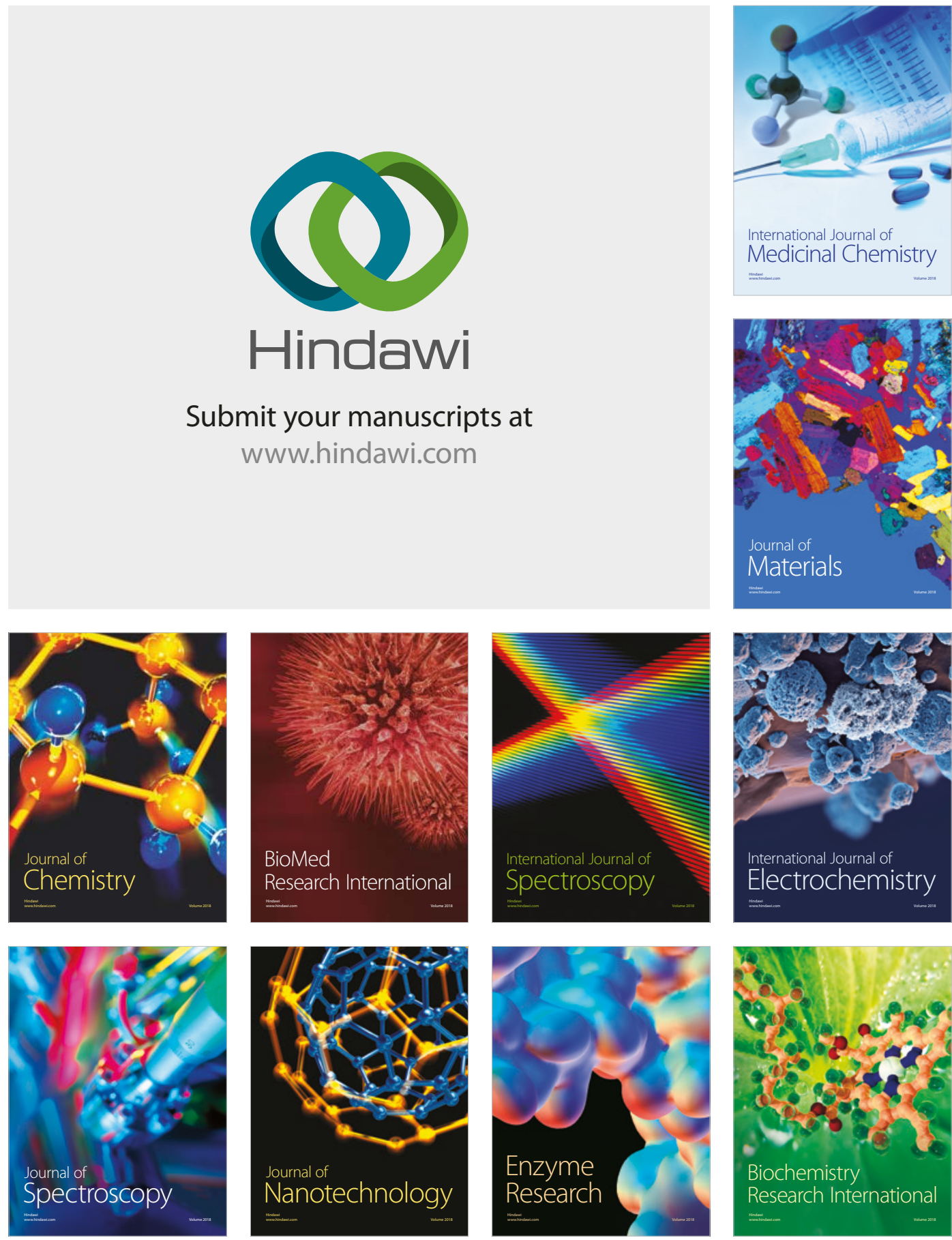
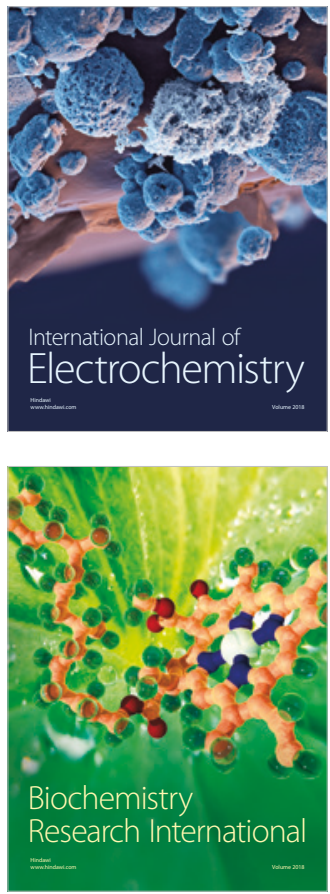